\title{
Soil Water Retention Modeling Using Pedotransfer Functions
}

\author{
R. K. Jaiswal, ${ }^{1}$ T. Thomas, ${ }^{1}$ R. V. Galkate, ${ }^{1}$ and Jaivir Tyagi $^{2}$ \\ ${ }^{1}$ Scientist, GPSRC National Institute of Hydrology, WALMI Campus Kolar Road, Bhopal, Madhya Pradesh 462016, India \\ ${ }^{2}$ Scientist, National Institute of Hydrology, Jal Vigyan Bhavan, Roorkee, Uttarakhand 247667, India \\ Correspondence should be addressed to R. K. Jaiswal; rkjaiswal_sagar@yahoo.co.in
}

Received 15 September 2013; Accepted 5 November 2013

Academic Editors: J. Mohammadi and D. Zeng

Copyright (C) 2013 R. K. Jaiswal et al. This is an open access article distributed under the Creative Commons Attribution License, which permits unrestricted use, distribution, and reproduction in any medium, provided the original work is properly cited.

\begin{abstract}
The unsaturated hydraulic functions are key input data in numerical models of vadose zone processes. The direct measurement of soil moisture at different suction heads requires detailed analysis of soil samples with sophisticated instruments which can be replaced with the help of pedotransfer functions (PTFs) which are empirical relationships between the soil hydraulic properties and the more easily obtainable basic soil properties. The CalcPTF software has been used to compute the parameters of the most commonly used models of Brooks and Corey (BC) and Van Genuchten (VG) from PTFs for determination of soil water retention curves on seventeen sites in the commands of Benisagar and Rangawan reservoirs in Chhatarpur district (MP), India. The parameters of sixteen PTFs have been estimated and results have been compared with observed data using root mean square error (RMSE), coefficient of determination $\left(R^{2}\right), R_{\text {adj }}^{2}$, and graphical representation. The PTF of BC model suggested by Rawls and Brakensiek, 1985 (BC-RB), has been found to be the best-fit PTF for sites 1, 2, 5, 6, 10, 11, 14, 15, and 17, where BC model by Saxton et al., 1986 (BC-SEL), can be used for modeling the soil moisture for sites 3, 4, 9, 12, and 16. It may be concluded that the PTF suggested by Rawls and Brakensiek, 1985 (BC-RB), or Saxton et al., 1986 (BC-SEL), can be used for computation of soil moisture retention curves in the region.
\end{abstract}

\section{Introduction}

The common conceptual models for unsaturated flow often rely on the oversimplified representation of medium pores as a bundle of cylindrical capillaries and assume that soil water pressure head is attributed to capillary forces only and ignores the adsorptive surface forces. Hence, it is often assumed that aqueous flow is negligible when a soil is near or at residual water content $\left(\theta_{r}\right)$. The reason for the finite value of $\theta_{r}$ is that the dominant historical water-content measurements were in the wet range, and the typical soil water retention models assumed asymptotic behavior at low water content values. It is generally treated as a fitting parameter. Hence, an effective saturation is often defined as $S_{e}=\left(\theta-\theta_{r}\right) /\left(\theta_{s}-\theta_{r}\right)$ with $\theta$ being water content and $\theta_{s}$ the saturated water content [1]. To use the model, additional parameters must be known to quantify the contribution of film flow. Several functions have been proposed to empirically describe the soil water retention curve. These models were based on Rechards equation for flow of water in saturated or partly saturated soil. One of the most popular functions has been the equation given by
Brooks and Corey in 1964 (BC) [2] which describes effective saturation $\left(S_{e}\right)$ as

$$
\begin{gathered}
S_{e}=\left[\frac{h_{b}}{h}\right]^{\lambda} \quad h>h_{b}, \\
S_{e}=1 \quad h \leq h_{b},
\end{gathered}
$$

where $h$ is the suction head and $h_{b}$ and $\lambda$ are the parameters referred to as the air entry head and pore size distribution index, respectively. After the model proposed by Brooks and Corey, several differentiable equations of complex equations have been suggested by researchers ([3-9], etc.). These equations were able to produce the soil water retention curve accurately but most of them were complex in nature. Van Genuchten proposed a modification with a simple representation of soil water retention represented as VG model here as [10]

$$
S_{e}=\frac{1}{\left[1+(\alpha h)^{n}\right]^{m}},
$$


where $\alpha, n$, and $m$ are empirical constants with $m=1-1 / n$. All these models presented here require observed values of soil moisture at different suction, but sometimes these observations may not be available and various studies have been conducted to correlate model parameters of soil retention curve with easily available and measurable soil properties in the form of empirical relationships called pedotransfer functions (PTFs). The pedotransfer functions (PTFs) are empirical relationships between the soil hydraulic properties and the more easily obtainable basic soil properties available from soil surveys. The use of PTFs is necessary when the simulations have to be done for large-scale projects or for pilot studies [11]. Various PTFs have been suggested by researchers for computation of parameters of BC and VG models of soil water retention curve [12-25]. An excel macro "CalcPTF" [26] has been applied after carrying out detailed soil testing in the commands of Benisagar and Rangawan reservoir in Chhatarpur district of Madhya Pradesh (India). These PTFs used percentage of clay, silt, sand, organic content, and bulk density of soils for computation of parameters of $\mathrm{BC}$ or VG model.

\section{Study Area}

Two adjacent commands in Benisagar and Rangawan reservoir projects located in Chhatarpur district of Madhya Pradesh (India) have been selected for the study. The location map of Benisagar and Rangawan irrigation project in Chhatarpur district of Madhya Pradesh has been given in Figure 1. The Benisagar reservoir is situated near the historical town Khajuraho in Rajnagar tehsil of the Chhatarpur district. The gross storage capacity and dead storage capacity of the Benisagar reservoir are $27.59 \mathrm{MCM}$ and $1.37 \mathrm{MCM}$, respectively. The gross command area of the project is 6802.46 hectares while the cultivated area is 6267 hectare. The proposed irrigable area in the command through dam is 4170 hectare with proposed cropping pattern consist of Mexican wheat in 3000 hectares, ordinary wheat in 300 hectare and soybean in 870 hectare. Two canals from both ends of the dam have been constructed to feed the command area.

The Rangawan project is a major interstate irrigation project of Madhya Pradesh (M.P.) and Uttar Pradesh (U.P.), situated near village Rangawan in Rajnagar Tahsil of Chhatarpur district. The length of the main canal is $14 \mathrm{~km}$ having a head discharge of $8.27 \mathrm{~m}^{3} / \mathrm{sec}$. The soil samples from seventeen different sites in both commands considering different major soils in the study area have been collected and pressure plate apparatus has been used to determine soil moisture at various suction on soil samples (Figure 2). The soil texture, bulk density, and organic content of all soil samples have been determined using standard procedures for computation of PTFs.

\section{Methodology}

In the present study, an attempt has been made to apply PTF-based models of soil retention for application of solute transport and water balance in command and determination of parameters of the best suited model for different sites in the study area. In the study, sixteen PTFs have been applied for determination of parameters of Brooks and Corey (BC) and Van Genuchten (VG) models using CalcPTF Macro in Excel.

3.1. Pedotransfer Function-Based Models. The observed data of soil moisture retentions are rarely available especially in developing countries like India, and PTF based model may be useful in which model parameters are computed using easily available soil properties such as texture, bulk density, and organic content. The CalcPTF Macro has been used to compute the parameters of 7 PTFs for BC model and 9 PTFs for VG model. The data required for estimation of parameters of models have been presented in Table 1 and the detailed information about PTFs can be seen in the manual of CalcPTF [26].

3.2. Evaluation of Performance. The performance of different analytical and PTF models has been judged with the help of different robust criterion including root mean square error (RMSE), coefficient of determination $\left(R^{2}\right)$, and $R_{\text {adj }}^{2}$. The RMSE is an indicator for representation of the overall error of the evaluated function and should approach to zero for best model performance. The $R_{\text {adj }}^{2}$ was suggested to take the impact of the number of parameters of model on performance and reflect the degree of correlation between observed and fitted data and statistically can take any value $\leq 1$. The equation for computation of different performance evaluators has been given below as

$$
\begin{aligned}
& \text { RMSE }= \sqrt{\frac{\sum_{i=1}^{N}\left(\theta_{i}^{\text {obs }}-\theta_{i}^{\text {comp }}\right)^{2}}{N},} \\
& R^{2}=1-\frac{\mathrm{SSE}}{\mathrm{SST}} \\
& R_{\mathrm{adj}}^{2}=\frac{(N-1) R^{2}-(p-1)}{N-p},
\end{aligned}
$$

where $\theta_{i}^{\text {obs }}, \theta_{i}^{\text {comp }}$ are the $i$ th observed and computed value of soil moisture, $N$ is the number of data, SSE is the model sum of square, SST is the total sum of square, and $p$ is the number of model parameters. The SSE and SST can be computed using the following equations:

$$
\begin{gathered}
\text { SST }=\sum_{i=1}^{N}\left(\theta_{i}^{\text {comp }}-\bar{\theta}^{\text {comp }}\right) \\
\text { SSE }=\sum_{i=1}^{N}\left(\theta_{i}^{\text {obs }}-\theta_{i}^{\text {comp }}\right),
\end{gathered}
$$

where $\bar{\theta}^{\text {comp }}$ is the mean of computed values.

\section{Analysis of Results}

The soil, plant, and atmosphere act as a continuum along which soil water moves in response to gradients in energy. 


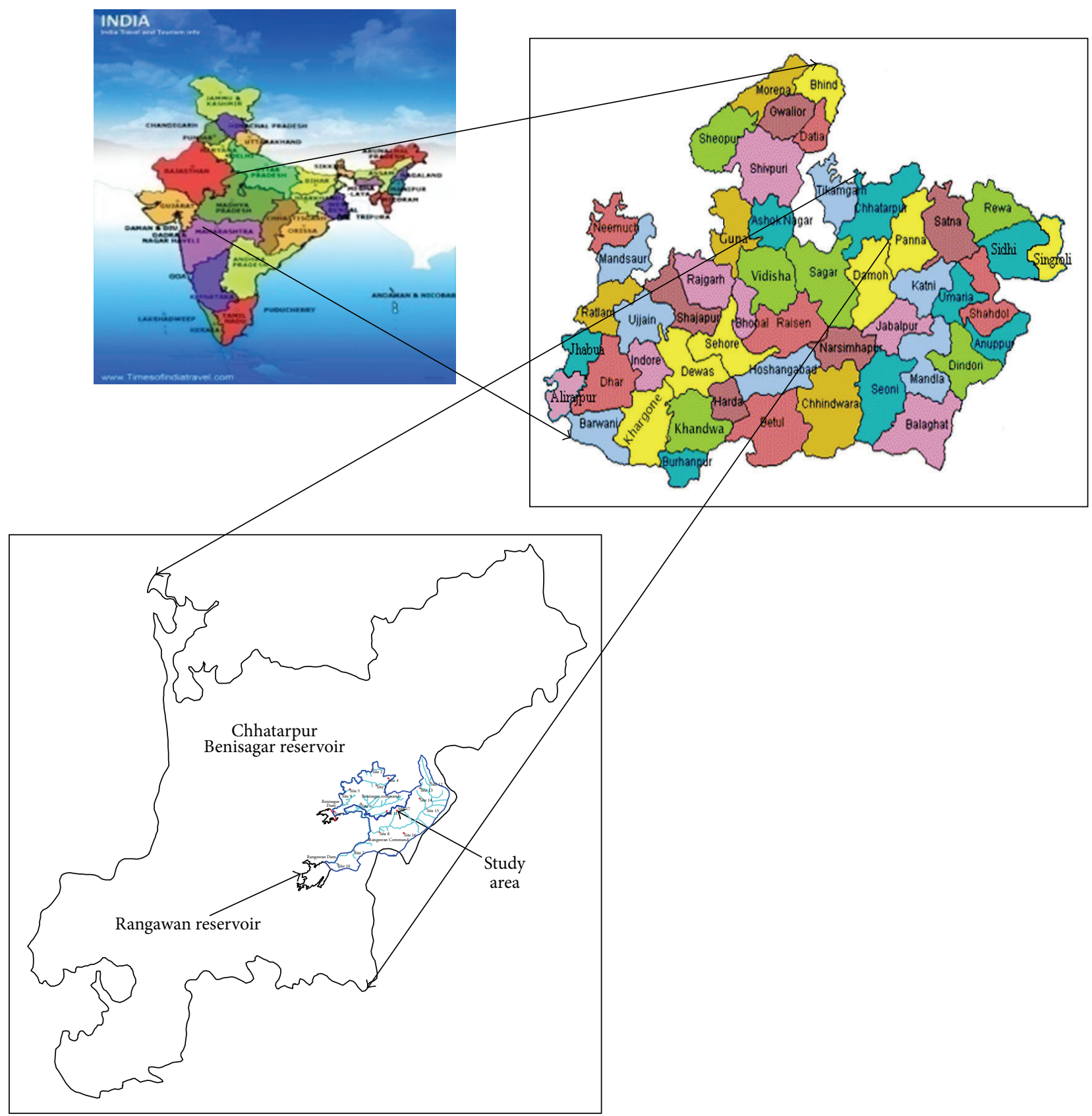

Figure 1: Base map of the study area.

The energy potential of the water relative to that of pure water helps determine the amount of water stored in the soil, moved through the soil, and moved into and through the plant to the transpiring surface of the leaf. In the present study, the soil samples from seventeen sites covering most of the soils in Benisagar and Rangawan commands have been analyzed. From the analysis of results, it has been observed that the PTF suggested by Rawls and Brakensiek, 1985 (BC-RB), has been found the most suited PTF for determination of soil moisture retention curve for site- 1 , site- 2 , site- 5 , site- 6 , site10, site-11, site-14, site-15, and site-17, while the PTF for BC model by Saxton et al., 1986 (BC-SEL), has been found the most suited PTF to represent the curve for site-3, site-9, site12 , and site-16. The PTF given by Tomasella and Hodnett, 1998 (VG-TH), for computation of parameters of VG model has given the least RMSE and maximum value of $R^{2}$ for site-4, site-7, and site-13, while PTF by Campbell and Shiozawa, 1992 (BC-CS), for BC model has been judged as the best-fit model for site-8. From the analysis of results, it may be concluded that in the absence of observed data on soil moisture in the commands, the BC model can be used for computation of soil moisture at different suction pressure and the PTF suggested by Rawls and Brakensiek, 1985 (BC-RB), or Saxton et al., 1986 (BC-SEL), can be used for computation of parameters 


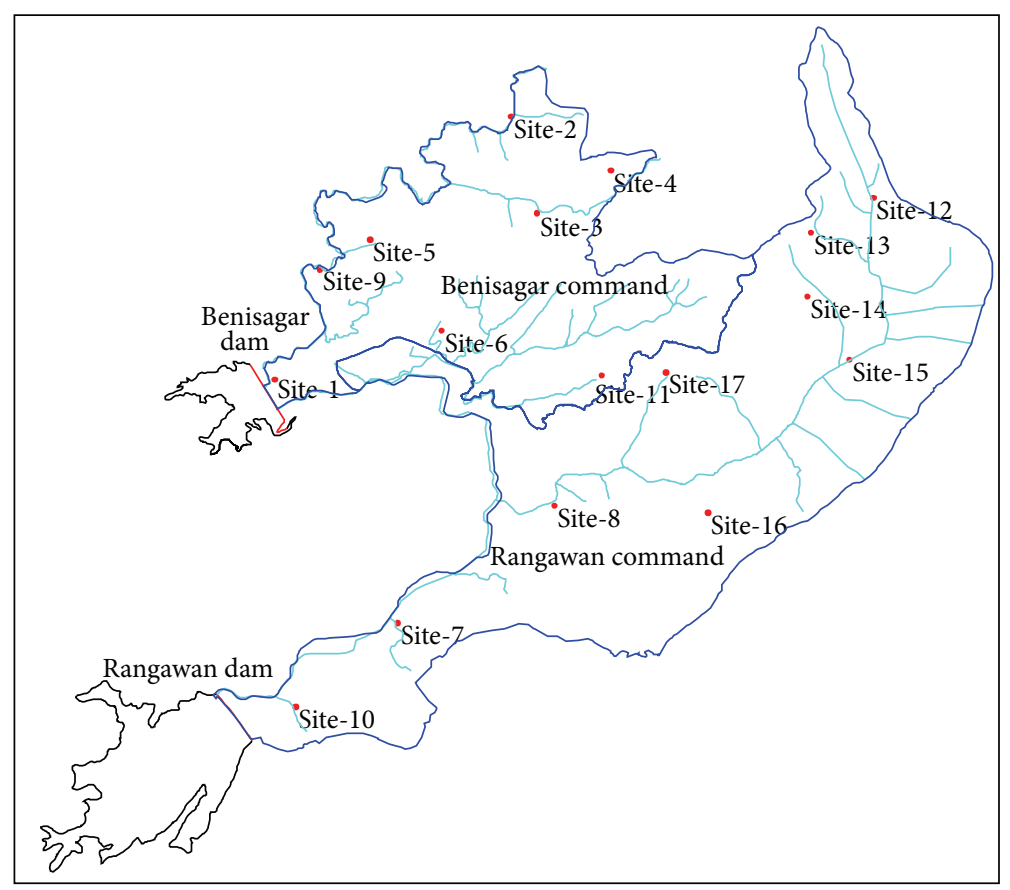

Figure 2: Location map of soil sampling sites.

TABLE 1: List of PTFs-based models used in the study.

\begin{tabular}{lc}
\hline Name of model & Soil properties used* \\
\hline Oosterveld and Chang, 1980 [16] (BC-OC) & Sand, clay, bulk density, depth \\
Rawls and Brakensiek, 1985 [14] (BC-RB) & Sand, clay, bulk density \\
Saxton et al., 1986 [12] (BC-SEL) & Sand, clay, bulk density \\
Campbell and Shiozawa, 1992 [13] (BC-CS) & Sand, clay, bulk density \\
Williams et al., 1992 [15] (BC-WIL1) & Sand, clay, bulk density \\
Williams et al., 1992 [15] (BC-WIL2) & Sand, clay, bulk density, organic carbon \\
Mayr and Jarvis, 1999 [17] (BC-MJ) & Sand, clay, bulk density, organic carbon \\
Varallyay et al., 1982 [19] (VG-VAEL) & clay, bulk density \\
Vereecken et al., 1989 [20] (VG-VEEL) & Sand, clay, bulk density, organic carbon \\
Wösten et al., 1999 [18] (VG-WOEL1) & Sand, silt, clay, depth \\
Wösten et al., 1999 [18] (VG-WOEL2) & Silt, clay, bulk density, organic carbon, depth \\
Gupta and Larson, 1979 [23] (VG-GL) & Sand, silt, clay, bulk density, organic carbon \\
Rawls et al., 1982 [22] (VG-REL1) & Sand, silt, clay, bulk density, organic carbon \\
Rawls et al., 1983 [25] (VG-REL2) & Sand, silt, clay, bulk density, organic carbon \\
Rajkai and Varallyay, 1992 [24] (VG-RV) & Sand, clay, bulk density, organic carbon \\
Tomasella and Hodnett, 1998 [21] (VG-TH) & Silt, clay, bulk density, organic carbon \\
\hline
\end{tabular}

${ }^{*}$ Sand, silt, clay, and organic carbon in \%, bulk density in $\mathrm{g} / \mathrm{cm}^{3}$, and depth in $\mathrm{m}$.

of BC model. The observed and computed soil moisture at a different suction head for few sites has been given in Figure 3. The CalcPTF Macro in Excel has been used to determine the parameters of various PTF-based models at different sites of Benisagar and Rangawan commands area. The observed and computed values of soil moisture have been computed with the help of root mean square error (RMSE), coefficient of determination $\left(R^{2}\right)$, and $R_{\text {adj }}^{2}$. The best suited PTF models, and their parameters for different sites have been presented in Table 2.
From the analysis of results, it has been observed that the PTF suggested by Rawls and Brakensiek, 1985 (BC-RB), has been found to be the most suited PTF for determination of soil moisture retention curve for site-1, site- 2 , site- 5 , site- 6 , site-10, site-11, site-14, site-15, and site-17, while the PTF for BC model by Saxton et al., 1986 (BC-SEL), has been found to be the most suited PTF to represent the curve for site-3, site-9, site-12, and site-16. The PTF given by Tomasella and Hodnett, 1998 (VG-TH), for computation of parameters of VG model has given the least RMSE and maximum value of $R^{2}$ for site-4, 

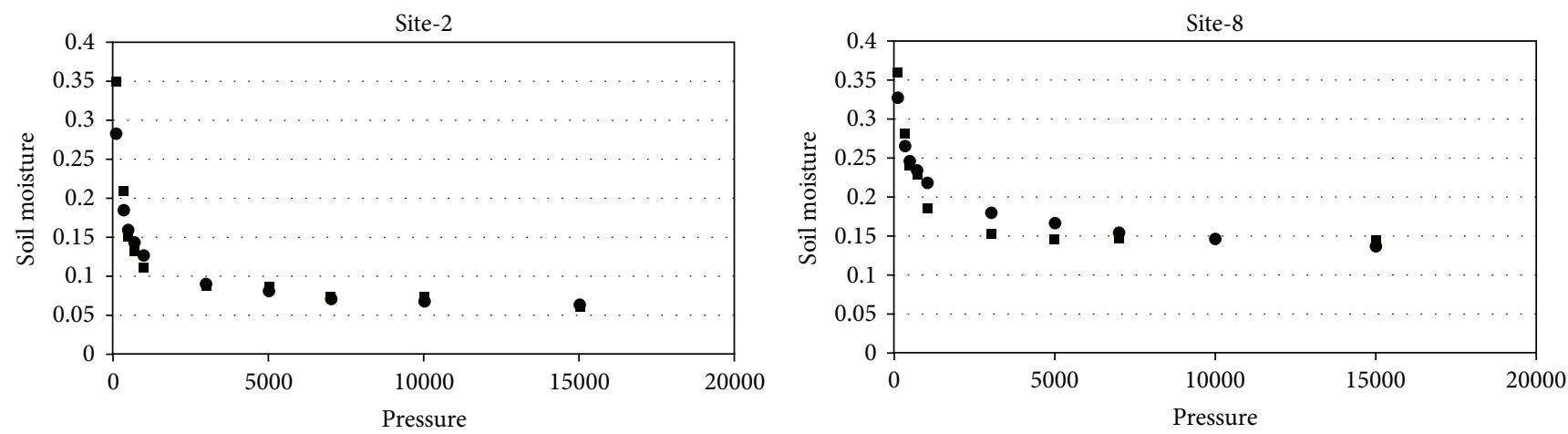

- Comp (BC-RB)

- Comp (BC-CS)

- Obs

- Obs

(a)

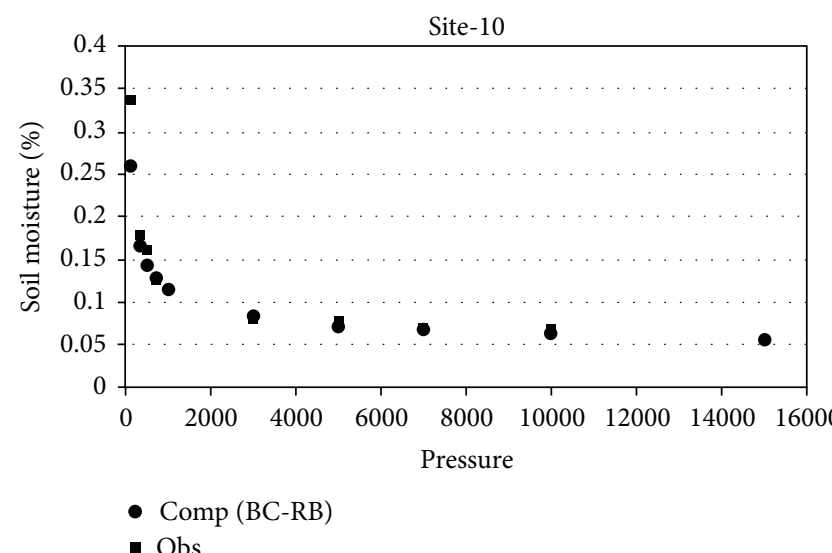

(c)

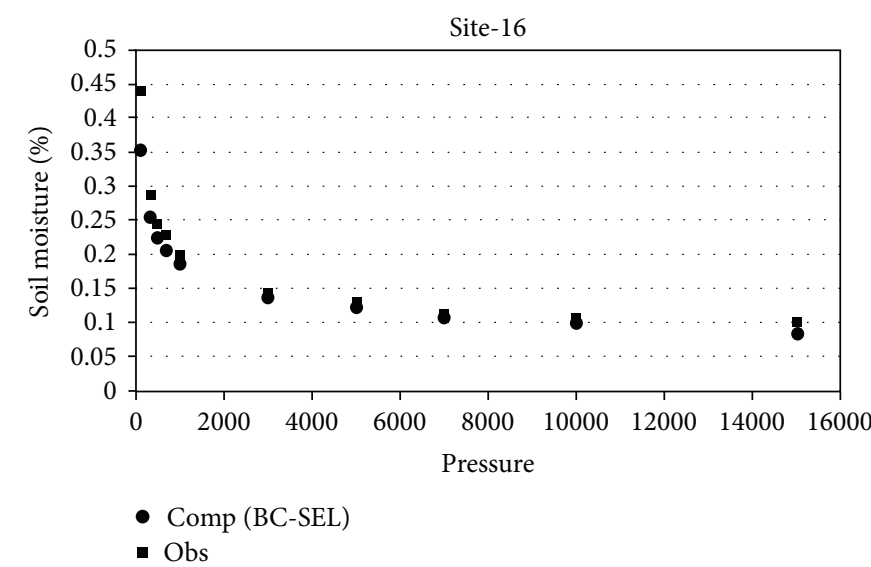

(d)

FIGURE 3: Comparison of computed and observed soil water retention curve from best-fit model for few sites in commands.

TABLE 2: Best-fit PTF-based models and their parameters in Benisagar and Rangawan commands.

\begin{tabular}{|c|c|c|c|c|c|c|c|c|}
\hline \multirow{2}{*}{ Site } & \multirow{2}{*}{ Best-fit PTF } & \multirow{2}{*}{ Model type } & \multicolumn{6}{|c|}{ RMSE and model parameters } \\
\hline & & & RMSE & $\theta_{r}$ & $\theta_{s}$ & $h_{b}(\mathrm{BC}) / a(\mathrm{VG})$ & $\lambda(\mathrm{BC}) / n(\mathrm{VG})$ & $m(\mathrm{VG})$ \\
\hline Site-1 & Rawls and Brakensiek, 1985 [14] (BC-RB) & $\mathrm{BC}$ & 0.02 & 0.03 & 0.43 & 37.90 & 0.39 & - \\
\hline Site-2 & Rawls and Brakensiek, 1985 [14] (BC-RB) & $\mathrm{BC}$ & 0.02 & 0.03 & 0.39 & 40.40 & 0.41 & - \\
\hline Site-3 & Saxton et al., 1986 [12] (BC-SEL) & $\mathrm{BC}$ & 0.02 & 0 & 0.31 & 222.12 & 0.30 & - \\
\hline Site- 4 & Tomasella and Hodnett, 1998 [21] (VG-TH) & VG & 0.01 & 0.03 & 0.60 & 0.02 & 1.27 & 0.21 \\
\hline Site-5 & Rawls and Brakensiek, 1985 [14] (BC-RB) & $\mathrm{BC}$ & 0.03 & 0.03 & 0.37 & 45.32 & 0.42 & - \\
\hline Site-6 & Rawls and Brakensiek, 1985 [14] (BC-RB) & $\mathrm{BC}$ & 0.03 & 0.03 & 0.39 & 42.67 & 0.42 & - \\
\hline Site-7 & Tomasella and Hodnett, 1998 [21] (VG-TH) & VG & 0.03 & 0 & 0.56 & 0.035 & 1.25 & 0.20 \\
\hline Site- 8 & Campbell and Shiozawa, 1992 [13] (BC-CS) & $\mathrm{BC}$ & 0.02 & 0 & 0.38 & 42.34 & 0.17 & - \\
\hline Site-9 & Saxton et al., 1986 [12] (BC-SEL) & $\mathrm{BC}$ & 0.03 & 0 & 0.38 & 75.34 & 0.29 & - \\
\hline Site-10 & Rawls and Brakensiek, 1985 [14] (BC-RB) & $\mathrm{BC}$ & 0.02 & 0.03 & 0.37 & 39.19 & 0.43 & - \\
\hline Site-11 & Rawls and Brakensiek, 1985 [14] (BC-RB) & $\mathrm{BC}$ & 0.01 & 0.03 & 0.36 & 17.57 & 0.51 & - \\
\hline Site-12 & Saxton et al., 1986 [12] (BC-SEL) & $\mathrm{BC}$ & 0.02 & 0 & 0.42 & 61.72 & 0.29 & - \\
\hline Site-13 & Tomasella and Hodnett, 1998 [21] (VG-TH) & VG & 0.01 & 0.02 & 0.59 & 0.02 & 1.26 & 0.21 \\
\hline Site-14 & Rawls and Brakensiek, 1985 [14] (BC-RB) & $\mathrm{BC}$ & 0.01 & 0.03 & 0.33 & 70.86 & 0.42 & - \\
\hline Site-15 & Rawls and Brakensiek, 1985 [14] (BC-RB) & $\mathrm{BC}$ & 0.02 & 0.03 & 0.38 & 54.051 & 0.39 & - \\
\hline Site-16 & Saxton et al., 1986 [12] (BC-SEL) & $\mathrm{BC}$ & 0.03 & 0 & 0.36 & 95.19 & 0.28 & - \\
\hline Site-17 & Rawls and Brakensiek, 1985 [14] (BC-RB) & $\mathrm{BC}$ & 0.03 & 0.04 & 0.39 & 37.59 & 0.41 & - \\
\hline
\end{tabular}


site-7, and site-13, while PTF by Campbell and Shiosawa, 1992 (BC-CS), for BC model has been judged as the best-fit model for site-8. From the analysis of results, it may be concluded that in the absence of observed data on soil moisture in the commands, the BC model can be used for computation of soil moisture at a different suction pressure and the PTF suggested by Rawls and Brakensiek, 1985 (BC-RB), or Saxton et al., 1986 (BC-SEL), can be used for computation of parameters of $\mathrm{BC}$ model. The observed and computed soil moisture at a different suction head for few sites has been given in Figure 3.

\section{Conclusions}

The PTF-based equations for determination of available water content have been found useful in developing countries because of correlating soil moisture with easily measurable physical properties of soil such as bulk density, organic matter content, and particle-size distribution. In the study, the parameters of 7 PTFs of BC model and 9 PTFs of VG model have been determined for the commands of Benisagar and Rangawan reservoirs in Madhya Pradesh (India). The goodness of fit criteria including RMSE, $R^{2}$, and $R_{\text {adj }}^{2}$ confirmed that PTFs suggested by Rawls and Brakensiek, 1985 (BC-RB), are found to be the most suitable for site-1, site-2, site- 5 , site- 6 , site-10, site-11, site-14, site-15, and site-17, where BC model by Saxton et al., 1986 (BC-SEL), can be used for modeling the soil moisture for site-3, site-9, site-12, and site16. The VG model with PTF given by Tomasella and Hodnett, 1998 (VG-TH), can be used for site-4, site-7, and site-13. It may be concluded from the study that Brooks and Corey's model may be used for determination of soil water retention curve for soils in the region and in the absence of observed data on soil moisture retention, the PTF suggested by Rawls and Brakensiek, 1985 (BC-RB), can be used for determination of model parameters of $\mathrm{BC}$ model in the region.

\section{References}

[1] F. Zhang, Soil Water Retention and Relative Permeability for Full Range of Saturation, U.S. Department of Commerce, Springfield, Va, USA, 2010.

[2] R. H. Brooks and A. T. Corey, Hydraulic Properties of Porous Media, vol. 3 of Hydrology Papers, Colorado State University, Fort Collins, Colo, USA, 1964.

[3] L. G. King, "Description of soil characteristics for partially saturated flow," Proceedings of Soil Science Society of America, vol. 29, pp. 359-362, 1965.

[4] W. C. Visser, "An empirical expression for the desorption curve," in Water in the Unsaturated Zone: Proceeding of Wageningen Symposium, P. E. Rijtema and H. Wassink, Eds., vol. 1, pp. 329335, IASH/AIHS, Unesco, Paris, France, 1968.

[5] M. J. Fayer and C. S. Simmons, "Modified soil water retention functions for all matric suctions," Water Resources Research, vol. 31, no. 5, pp. 1233-1238, 1995.

[6] H. J. Morel-Seytoux and J. R. Nimmo, "Soil water retention and maximum capillary drive from saturation to oven dryness," Water Resources Research, vol. 35, no. 7, pp. 2031-2041, 1999.
[7] S. W. Webb, "A simple extension of two-phase characteristic curves to include the dry region," Water Resources Research, vol. 36, no. 6, pp. 1425-1430, 2000.

[8] P. H. Groenevelt and C. D. Grant, "A new model for the soilwater retention curve that solves the problem of residual water contents," European Journal of Soil Science, vol. 55, no. 3, pp. 479-485, 2004.

[9] M. Khlosi, W. M. Cornelis, D. Gabriels, and G. Sin, "Simple modification to describe the soil water retention curve between saturation and oven dryness," Water Resources Research, vol. 42, no. 11, Article ID W11501, 2006.

[10] M. T. van Genuchten, "A closed-form equation for predicting the hydraulic conductivity of unsaturated soils," Soil Science Society of America Journal, vol. 44, no. 5, pp. 892-898, 1980.

[11] Y. A. Pachepsky and W. J. Rawls, in Development of Pedotransfer Functions in Soil Hydrology (Developments in Soil Science), vol. 30, Elsevier, Amsterdam, The Netherlands, 2004.

[12] K. E. Saxton, W. J. Rawls, J. S. Romberger, and R. I. Papendick, "Estimating generalized soil-water characteristics from texture," Soil Science Society of America Journal, vol. 50, no. 4, pp. 10311036, 1986.

[13] G. S. Campbell and S. Shiozawa, "Prediction of hydraulic properties of soils using particle-size distribution and bulk density data," in Indirect Methods for Estimating the Hydraulic Properties of Unsaturated Soils, T. M. van Genuchten, F. J. Leij, and L. J. Lund, Eds., pp. 317-328, University of California, Riverside, Calif, USA, 1992.

[14] W. J. Rawls and D. L. Brakensiek, "Prediction of soil water properties for hydrologic modeling," in Proceedings of the Symposium on Watershed Management in the Eighties, E. B. Jones and T. J. Ward, Eds., pp. 293-299, New York, NY, USA, 1985.

[15] J. Williams, P. Ross, and K. Bristow, "Predictions of the Campbell water retention function from texture, structure, and organic matter," in Proceedings of the International Workshop on Indirect Methods for Estimating the Hydraulic Properties of Unsaturated Soils, M. T. van Genuchten, F. J. Leij, and L. J. Lund, Eds., pp. 427-442, University of California, Riverside, Calif, USA, 1992.

[16] M. Oosterveld and C. Chang, "Empirical relations between laboratory determinations of soil texture and moisture retention," Canadian Agricultural Engineering, vol. 22, no. 2, pp. 149-151, 1980.

[17] T. Mayr and N. J. Jarvis, "Pedotransfer functions to estimate soil water retention parameters for a modified Brooks-Corey type model," Geoderma, vol. 91, no. 1-2, pp. 1-9, 1999.

[18] J. H. M. Wösten, A. Lilly, A. Nemes, and C. le Bas, "Development and use of a database of hydraulic properties of European soils," Geoderma, vol. 90, no. 3-4, pp. 169-185, 1999.

[19] G. Varallyay, K. Rajkai, Y. A. Pachepsky, and R. A. Shcherbakov, "Mathematical description of soil water retention curve," Pochvovedenie, vol. 4, pp. 77-89, 1982 (Russian).

[20] H. Vereecken, J. Maes, J. Feyen, and P. Darius, "Estimating the soil moisture retention characteristic from texture, bulk density, and carbon content," Soil Science Society of America Journal, vol. 148, no. 6, pp. 389-403, 1989.

[21] J. Tomasella and M. G. Hodnett, "Estimating soil water retention characteristics from limited data in Brazilian Amazonia," Soil Science, vol. 163, no. 3, pp. 190-202, 1998.

[22] W. J. Rawls, D. L. Brakensiek, and K. E. Saxton, "Estimation of soil water properties," Transactions of the American Society of Agricultural Engineers, vol. 25, no. 5, pp. 1316-1320, 1982. 
[23] S. C. Gupta and W. E. Larson, "Estimating soil water retention characteristics from particle size distribution, organic matter percent, and bulk density," Water Resources Research, vol. 15, no. 6, pp. 1633-1635, 1979.

[24] K. Rajkai and G. Varallyay, "Estimating soil water retention from simpler properties by regression techniques," in Proceedings of the International Workshop on Indirect Methods for Estimating the Hydraulic Properties of Unsaturated Soils, M. T. van Genuchten, F. J. Leij, and L. J. Lund, Eds., pp. 417-426, University of California, Riverside, Calif, USA, 1992.

[25] W. J. Rawls, D. L. Brakensick, and B. Soni, "Agricultural management effects on soil water processes. Part I: soil water retention and Green and Ampt infiltration parameters," Transactions of the American Society of Agricultural Engineers, vol. 26, no. 6, pp. 1747-1752, 1983.

[26] A. K. Guber and Y. A. Pachepsky, Multimodeling with Pedotransfer Functions, Documentation and User Manual for PTF Calculator (CalcPTF), Environmental Microbial and Food Safety Laboratory, Hydrology and Remote Sensing Laboratory, Beltsville Agricultural Research Center, USDA-ARS, 2010. 

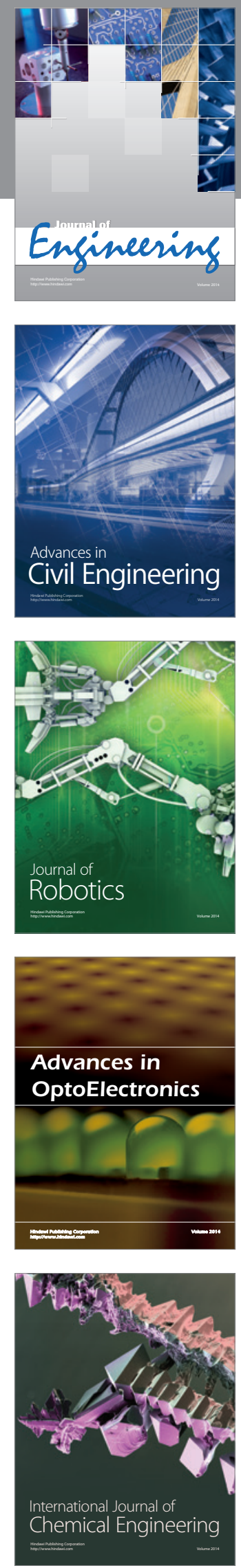

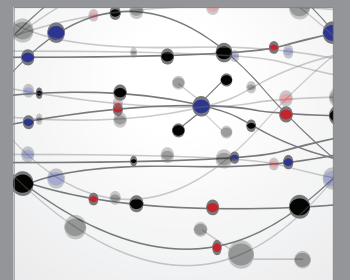

The Scientific World Journal
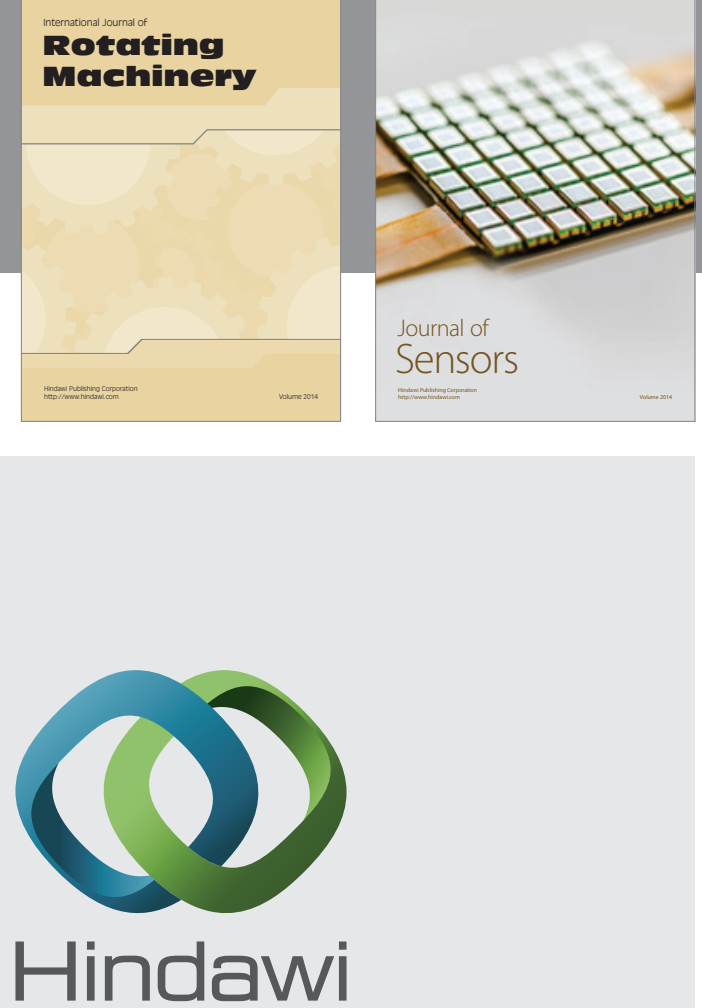

Submit your manuscripts at http://www.hindawi.com
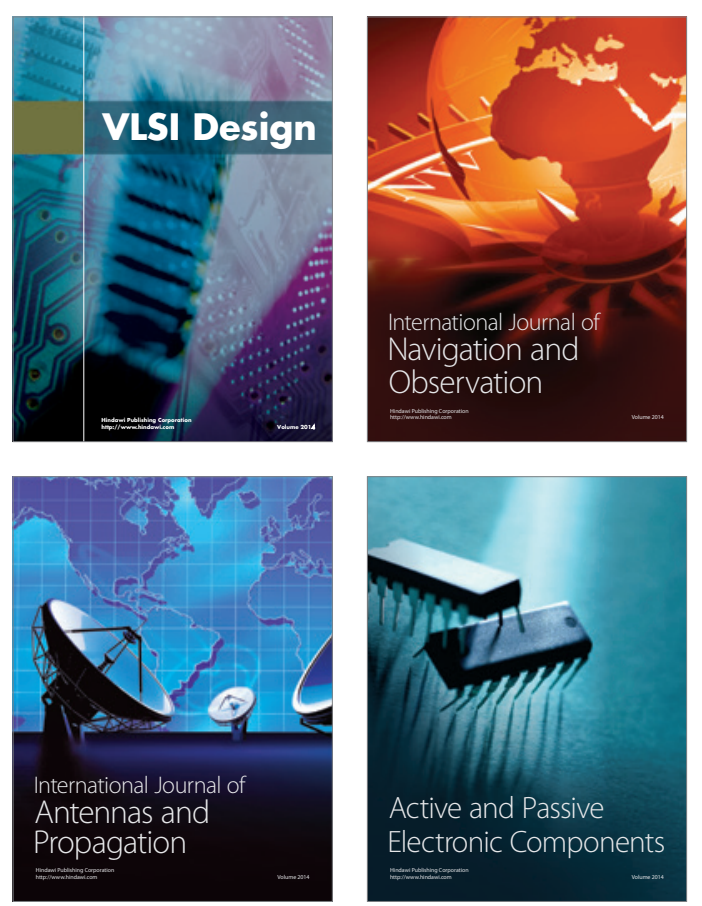
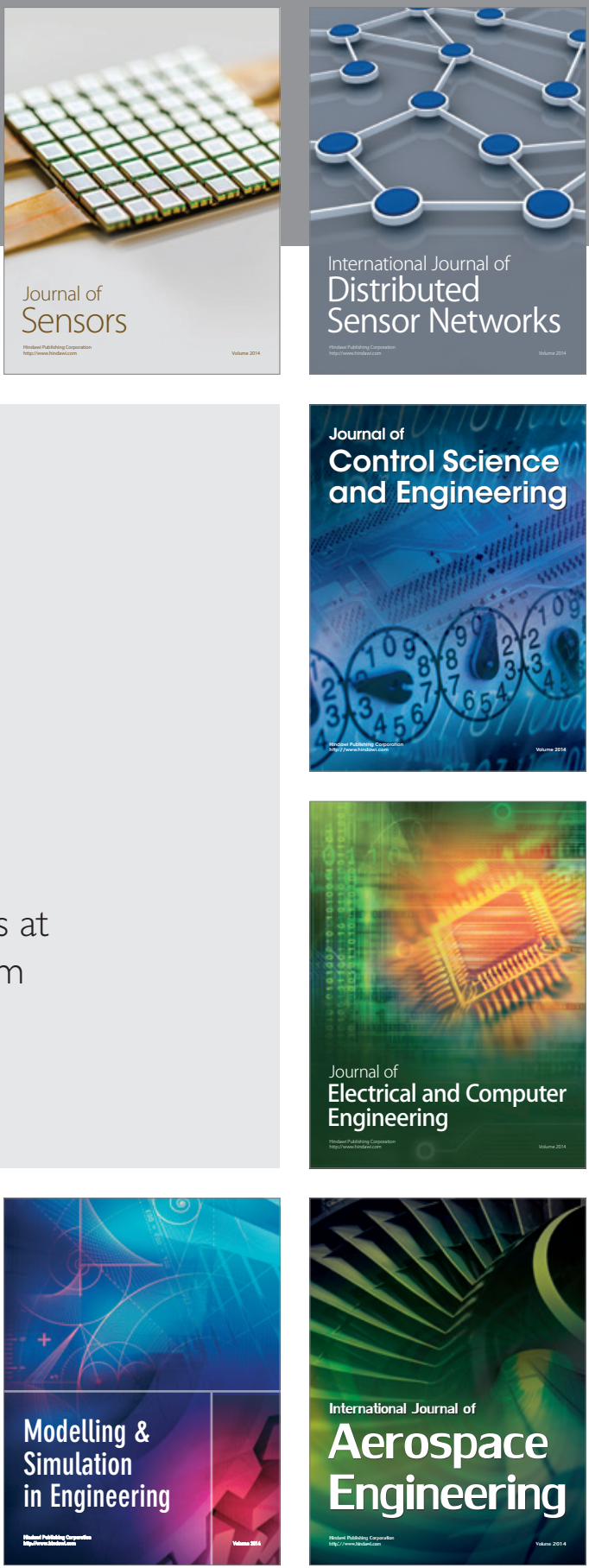

Journal of

Control Science

and Engineering
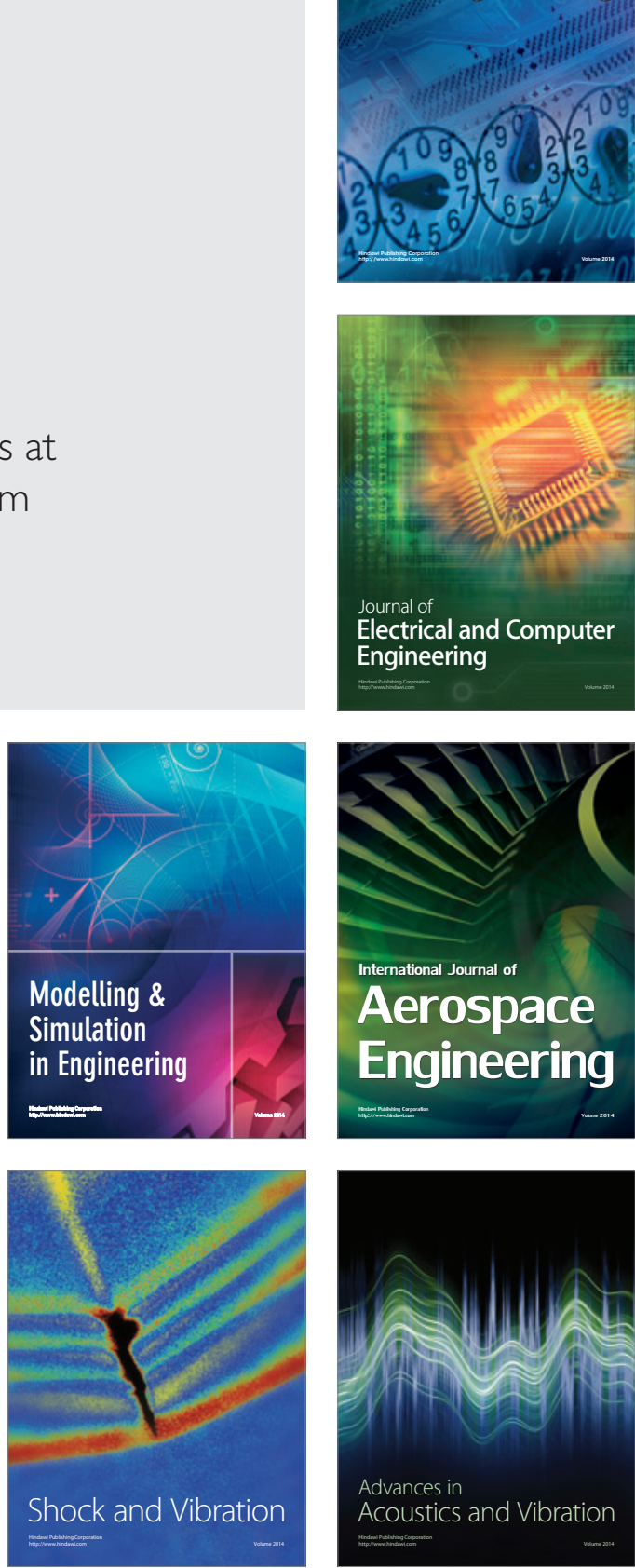